The $5^{\text {th }}$ International Conference on Family Business and Entrepreneurship

\title{
FINANCIAL SETTLEMENTS AND STRATEGIES OF DISCHARGED PATIENTS OF ST. ANTHONY COLLEGE OF ROXAS CITY, INC. (HOSPITAL)
}

\author{
Rea B. Barrera ${ }^{1}$, Nenita A. Beluso ${ }^{2}$ \\ ${ }^{1,2}$ Faculty of Business, Colegio de la Purisima Concepcion, Corresponding author: sgs@purisima.edu.ph
}

\begin{abstract}
The current crisis posed challenges to management of hospitals providing healthcare services where accounts receivable and payables are crucial to its continued operation. The study investigated the financial settlements and financial settlement strategies of discharged patients of St. Anthony College of Roxas City, Inc. (Hospital). Descriptivecorrelational design and simple random sampling were used. The respondents were 237 patients selected at random with outstanding balance upon discharge for the period of November to December 2020. Secondary data from patients' hospital records were utilized. Statistical tools used to analyse and interpret data were frequency count, percentage, mean, t-test, analysis of variance (ANOVA), and Pearson $r$. The extent of financial settlements and degree of financial settlement strategies were both high. Research found significant differences in the extent of financial settlements grouped as to medical health insurance, while no significant difference in terms of address, duration of hospitalization, and room accommodation. Further significant differences existed on the degree of financial settlement strategies with regard to address, medical health insurance, and duration of hospitalization whereas room accommodation showed negligible difference. The level of financial settlements was significantly associated with the degree of financial settlement strategies.
\end{abstract}

Keywords: Financial settlements, Strategies, Duration, Health insurance

\section{Introduction}

The management of accounts receivables and payables play a vital role in the balance sheets of producers of goods and services, Kriebel \& Yam, (2019) especially hospitals as providers of healthcare services. The yearly increase of delinquent payers, hospital bills and continued increase of patients and cases at this time of pandemic negatively impact hospital operations. Irrefutably, private hospitals depend largely on payments of patients for their services. In Uganda, detention of patients for non-payment of medical bills was common because citizens wrongly believed hospitals had the right to detain them (Wesaka, 2016). In many countries, patients were detained for non-payment of healthcare bills which occur both in public and private medical facilities wherein wide societal acceptance in certain countries assumed right of health providers to hold vulnerable people (Yates et al., 2017 for long periods in health facilities including the denial of vital services (Otremba et al., 2015). Relatively, in 2007 the Philippines enacted Republic Act (RA) 9439, prohibiting the Detention of Patients in Hospitals and Medical Clinics on Grounds of Nonpayment of Hospital Bills or Medical Expenses which hospitals abided by". As an effect, the implementation of the aforementioned statute resulted in several cases of unpaid bills among discharged patients of many hospitals across the country that compounded the impediment of hospitals. Aware of the realities, the research explored in what way private hospitals in the province of Capiz namely St. Anthony Hospital, Capiz Emmanuel Hospital, Capiz Doctors Hospital, and The Health Centrum Hospital find ways 
of financial settlements and strategies to discharged patients since they have not been spared from similar situations. Promissory note covering the patient's hospital expenses guaranteed by a mortgage or a comaker filed up as unpaid hospital dues (Acosta, 2018) though with signed and notarized documents for legal purposes. To date, hospitals are burdened with unsettled bills and have laid down and adopted strategies and schemes to discharge patients' financial responsibilities to be able to collect the amount and avoid declaration of bad debts. Data collected may be used for a more effective credit and collection policy, well-placed payment schemes and strategies, and an improved financial stability of the hospital.

\section{Statement of the Problem}

The study was conducted to investigate the financial settlements and financial settlement strategies of discharged patients of St. Anthony College of Roxas City, Inc. (Hospital). Specifically, it sought to answer the following questions:

1. What is the extent of financial settlements of discharged patients of the hospital as a whole and in terms of hospital bills and professional fees?

2. What is the degree of financial settlement strategies of the hospital as a whole and in terms of standalone risk and guaranteed payment?

3. Is there a significant difference in the extent of financial settlements when respondents are grouped according to address, medical health insurance, duration of hospitalization, and room accommodation?

4. Is there a significant difference in the degree of financial settlement strategies when respondents are grouped according to address, medical health insurance, duration of hospitalization, and room accommodation?

5. Is there a significant relationship between financial settlements and financial settlement strategies of discharged patients?

\section{Hypotheses of the Study}

The hypotheses of the study were the following:

1. There is no significant difference in the extent of financial settlements when respondents are grouped according to address, medical health insurance, duration of hospitalization, and room accommodation.

2. There is no significant difference in the degree of financial settlement strategies when respondents are grouped according to address, medical health insurance, duration of hospitalization, and room accommodation.

3. There is no significant relationship between financial settlements and financial settlement strategies of discharged patients.

\section{Theoretical Framework}

This study was anchored on Money and Credit Theory, Weber (1978) and Gitman \& Sacheva (2009), theory on financial management. The Money and Credit Theory was based on widespread use of money makes possible the valuation of delayed obligations in monetary terms, and thus facilitates debt. Delayed transactions such credit is geared to the probability that a future repayment will effectively take place. The notion of debt, then, always bridges a certain time span, extending from a past point of origin into a future point of repayment.

The aforementioned theories were appropriate to this study as they dealt with financial management, investment, credit management, and debts or unpaid bills of discharged patients, and management. The main objective of working capital management is to arrange the needed funds on the right time from the right source and for the right period, so that a trade-off between liquidity and profitability may be achieved. Furthermore, Weber (1978) defined debt as an obligation to pay a precisely quantified sum of money at a future point in time. Overdue transactions need future repayment and the notion of debt most often involves a certain time span.

\section{Conceptual Framework}

The framework of the study presents the socio-demographic profile of the respondents which included address, medical health insurance, duration of hospitalization, and room accommodation as the independent variable. While financial settlements of discharged patients were in terms of hospital bills and professional fees, and financial settlement strategies of discharged patients in terms of stand-alone risk and guaranteed payment were treated as the dependent variables. The research hypothesized that the demographic profile of the respondents may cause a variation on their extent of financial settlements and use of financial settlement strategies of discharged patients. Furthermore, the financial settlements of discharged patients 
are assumed to be related to the financial settlement strategies of discharged patients.

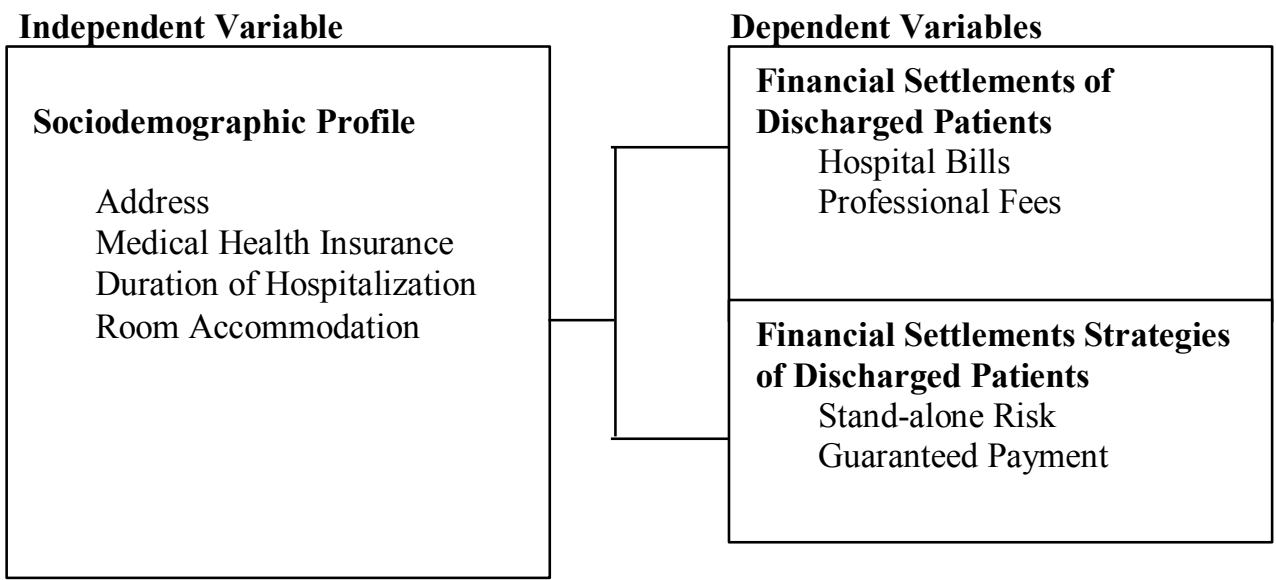

Figure 1. Schematic diagram on the relationship of the dependent and independent variables.

\section{Literature Review}

A good tax system should ensure that taxes are proportionate and certain (not arbitrary) and that the method of paying taxes is convenient to taxpayers. This includes offering taxpayers electronic systems for filing and paying taxes, merging taxes with the same tax base, allowing for self-assessment and having clear and efficient processes for refunding VAT cash refunds and undergoing tax audits. World Bank Group (2018), an electronic system for filing and paying taxes if implemented well and used by most taxpayers, benefits both tax authorities and firms.

China began its tax modernization program - which involved redefining tax shares between the various tax authorities and transitioning from turnover taxes to value added taxes - in the early 1990s. Since then, China has implemented numerous improvements to its tax system, including the introduction of a taxpayer services hotline in 2005, the formation of a specialized Taxpayer Services Department and online filing and payment for the major taxes in 2008, and a campaign to improve cooperation between the State Taxation Administration and local tax bureaus, provide electronic notices to taxpayers and reduce the number of tax filings for certain taxpayers in 2013. According to Leliya and Afiyah (2016) in their study entitled "The Effectiveness of Online Regional Tax Payment System in Increasing the Local Revenue of Cirebon City", revealed that in line with the rapid development of science and technology, the implementation of an online tax system is designed to facilitate the public in accessing information and provide ease in tax payment.

Online tax payments contribute to increased local revenue, for the online system in the payment of local taxes provides convenience for taxpayers in tax services, making the tax administration process more effective and keeping confidentiality of tax documents. Studies have shown that people tend to use online tax filing as it is more convenient and quicker than traditional paper tax filing. Electronic filing and payment systems improve the efficiency of the tax assessment method by increasing tax collection and reducing computation errors. income tax, value-added tax (VAT), payroll taxes and excise taxes] are most likely to use e-filing. Devano and Blessed (2006) states that awareness and compliance of taxpayer to meet their tax obligation depends not only on the technical issues that relate to the collection method, tax rates, technical inspection, investigation, penalties as the embodiment of the implementation of the provisions of the tax legislation, and service to taxpayers as the funder (term of paying taxes) of the state, but it also depends on the willingness of taxpayers, that is the extent to which the taxpayer is going to comply with tax laws. The authors further stated that the respondents find difficulty in using e-filing because of the unsuccessful attempts they encountered in filing tax returns due to not responding to e-filing websites. It is mandated to assess and collect all national internal revenue taxes, fees, and charges, and to enforce all forfeitures, penalties, and fines connected therewith, including the execution of judgments in all cases decided in its favor by the Court of Tax Appeals and the ordinary courts. The role of BIR in the national collection system can best be described by its Mission which is to raise revenues for the government through effective and efficient collection of taxes, quality service to taxpayers, and impartial and uniform enforcement of tax laws.

The payment of taxes is another important interaction between taxpayers (particularly businesses) and revenue bodies, and one where the use of information and communication technology (ICT) can deliver 
significant benefits to taxpayers, revenue bodies, government, and the financial sector. There are six objectives of the system which includes 1) providing taxpayers convenience in filing and paying their tax returns, 2) capturing returns data at source, 3) increasing and improving the reliability of returns data, 4) eliminating or minimizing encoding errors, 5) enhancing and facilitating the processing of tax returns and improving the security of tax payments, and 6) reducing costs and paper flow.

The Electronic Bureau of Internal Revenue Forms (eBIRForms) was developed primarily to provide taxpayers with an alternative mode of preparing and filing tax returns that is easier and more convenient (Revenue Regulations No. In the study conducted by Caasi et al (2015), wherein they used tax practitioners as respondents, results showed that the respondents believe that the use of the EFPS can improve tax collection due to its features on availability and convenience. Knowledge and understanding of taxation can improve the taxpayer compliance through the willingness to pay taxes; In order to increase use of the system, BIR has passed regulations that mandate the use of the electronic tax system for certain taxpayers in 2015 while penalties will be imposed for non-compliance.

According to GMA news written by TJ Dimacali, dated April 13, 2015 entitled "BIR's online system is incompatible with half of all PHL computers, data shows", the BIR's Electronic Filing and Payment System (eFPS) and Electronic BIR Forms (eBIRForms) - meant to facilitate the bureau's transition to a paperless tax system-were met with heavy criticism. Online tax filing systems have transformed traditional means of communication and interaction among taxpayers in many countries. However, in the perspective of current users of the online tax filing system in the Philippines, trust in technology highly affects their trust in e-government websites.

\section{Research Method}

The study used the descriptive-correlational research design. The relation of selected socio-demographic profiles of the respondents was determined with differences on the level of financial settlements and the extent of financial settlement strategies of discharged patients when grouped accordingly. The respondents were two hundred thirty-seven (237) patients randomly selected out of two hundred seventy-seven (277) discharged patients of St. Anthony College of Roxas City, Inc. (Hospital) with outstanding balance from the period of November 2020 to December 2020. Patients unable to settle their financial obligations were considered the persons settling their bills.

The Slovin formula was used for sample size calculation with 2.5 percent margin of error to determine the representative samples of a population. Simple random sampling using lottery technique to obtain the total sample size. The hospital records of discharged patients were accessed through permission from hospital authorities. Records included patients' profile, total hospital bills, payments made, and settlement strategies used when bills have not been fully settled. Data were tabulated in Microsoft Excel and processed using the Statistical Package for Social Sciences (SPSS). Frequency count and percentage were used to describe the profile of the respondents in terms of address, medical health insurance, duration of hospitalization, and room accommodation. While t-test and analysis of variance were used in determining the significant differences and Pearson $r$ for significant relationship between the level of financial settlements and extent of financial settlement strategies of discharged patients.

\section{Results and Discussion}

\section{Extent of Financial Settlements of Discharged Patients}

Results on extent of financial settlements of discharged patients of St. Anthony College of Roxas City, Inc. (Hospital) with a grand mean 4.04 was interpreted high. Finance office records on hospital bills and professional fees of discharged patients settled at 66-99 percent. Specifically, hospital bills and professional fees were described as high and the overall financial settlement was 79.05 percent. The results imply a high percentage of settlement of balances from accounts of discharged patients when taken as a whole. Normally, professional fees come in lesser amounts compared to the hospital bills except for surgical cases because of the high cost of surgical procedure. Records showed discharged patients or relatives pay a much higher attention to settling professional fees for attending physicians than their hospital bills. In (2017) where payments of bills only reached an average level of 65 percent and because of low collection rate, hospitals were grappling with huge financing problems. Often it is hard to collect debts from poor patients through normal legal channels. The hospital administrators made sure once payments were made by the patients, allocation for professional fees were secured and were released to the physicians. The result of the study contradicts Beck et al. 
Table 1. Extent of financial settlements of discharged patients as a whole.

\begin{tabular}{lcc}
\hline Indicators & Mean & Verbal Interpretation \\
\hline Hospital Bill & 3.86 & High \\
Professional Fees & 4.23 & High \\
Grand Mean & 4.04 & High \\
\hline
\end{tabular}

Hospital bill results showed 141 (59.5\%) of discharged patients had settled their hospital bills to a high extent including room accommodation, laboratories, and medicine taken from hospital pharmacy, 48 $(20.3 \%)$ moderate extent of settlement paying 3466 percent, $37(15.6 \%)$ very high extent of settlement paying 100 percent of their hospital bills balance, while the remaining $11(4.6 \%)$ or those who settled only 1-33 percent of their balances had low extent of financial settlement. It meant while there are balances for hospital bills, settlement was moderately high $(22.96 \%)$ remaining for unsettled accounts. Finance Office records showed financial settlement of 77.04 percent hospital bills on hospitalization expenses. Results corroborated Beck et al., (2017) findings 40 percent of the American citizens had problems with paying their medical bills and a very large portion of those owing medical bills have the desire to settle the accounts.

Table 2. Financial settlements of hospital bill

\begin{tabular}{lcc}
\hline \multicolumn{1}{c}{ Extent of Financial Settlement } & Frequency & Percent (\%) \\
\hline Very High (Fully Paid) & 37 & 15.6 \\
High (Paid 67-99\%) & 141 & 59.5 \\
Moderate (Paid 34-66\%) & 48 & 20.3 \\
Low (Paid 1-33\%) & 11 & 4.6 \\
Total & 237 & 100 \\
$\quad$ Mean Score $=(3.86$ high) & & \\
\hline
\end{tabular}

Professional fees. Results on number and percentage of discharged patients who settled charges of professional fees are entered in Table 1b. Professional fees vary depending on specialization and room accommodation. Professional fees are those which pertain to charges made by attending physicians. When respondents were taken as a whole, $103(43.5 \%)$ of discharged patients had settled professional fees at very high extent, 89 (37.6\%), extent of settlement was high at $42(17.7 \%)$ had moderate referring to settlement of 34-66 percent; while the remaining three $(1.3 \%)$ had low extent of settlement paying professional fees charges to about 1-33 percent. Finance Office records show financial settlement in terms of professional fees was 84.75 percent. This means the majority, charges for professional fees have been fully settled. Professional fees comprise 30 percent of the patients' total hospitalization bill while balances for professional fees, settlement was high with 15.25 percent remaining for unsettled accounts.

Table 3. Number and percentage distribution of patients in terms of the extent of financial settlement of professional fees.

\begin{tabular}{lcc}
\hline \multicolumn{1}{c}{ Extent of Financial Settlement } & Frequency & Percent (\%) \\
\hline & & \\
Very High (Fully Paid) & 103 & 43.5 \\
High (Paid 67-99\%) & 89 & 37.6 \\
Moderate (Paid 34-66\%) & 42 & 17.7 \\
Low (Paid 1-33\%) & 3 & 1.3 \\
Total & 237 & 100 \\
$\quad$ Mean Score $=4.23$ (High) & & \\
\hline
\end{tabular}

Degree of Financial Settlement Strategies of Discharged Patients

Means obtained for the degree of financial settlement strategies are presented in Table 4. Results had a grand mean of 3.48 described high. The degree of financial settlement strategies of discharged patients in terms of stand-alone risk had 3.44 mean and guaranteed payment was 3.52, both rated high. When taken as a whole, the 237 respondents' degree of financial settlement strategies of discharged patients had a mean of 3.48 verbally interpreted high. It implied patients made about 5-6 payments to settle their financial obligations with the hospital. Often, use of guarantee was frequently preferred. Patients or their folks were usually presented with options in settling their hospitalization bills. The amount per payment varied 
depending on the total amount of hospitalization bill, the availability of cash of the patients and availability of financial aids from sources like government agencies and nongovernmental organizations (NGOs). Findings gained support from O'Toole e al., (2014) claimed in settling debts, and enhanced progressive debt collection by the management, customers may need to negotiate and find ways to settle and pay their balances.

Table 4. Degree of financial settlement strategy of discharged patients as a whole.

\begin{tabular}{lcc}
\hline \multicolumn{1}{c}{ Indicator } & Mean & Verbal Interpretation \\
\hline Stand-Alone Risk & 3.44 & High \\
Guaranteed Payment & 3.52 & High \\
Grand Mean & 3.48 & High \\
\hline
\end{tabular}

Stand-alone risk. Results in Table 5 show the number and percentage of patients who used stand-alone risk as their financial settlement strategy. Out of 25 respondents who used stand-alone risk as their financial settlement strategy, 10 (40.0\%) patients had a high degree of financial settlement strategy. This means twofifths, 5-6 payments were made by them or their folks. There were seven $(28.0 \%)$ whose degree of financial settlement was low with 1-2 payments; four (16.0\%) very high with seven payments or more; and another four $(16.0 \%)$ had moderate financial settlement strategy who made 3-4 payments.

The results imply using stand-alone risk, patients or their folks made several payments to settle their financial obligations with the hospital. The patients were aware that if initial payments were not made, the bill would have accumulated to a bigger amount which can be difficult to pay in lump sum. When they pay their bills with money at hand, patients or their folks are able to avoid using the money on other less important expenses. The current financial state of the patient and lack of money upon admission was the reason. However, patients who were unable to find means to make initial payments upon admission were given time to find ways to settle their financial obligations. The results contradicted Jaymalin (2019) who emphasized that Filipinos cannot afford to pay their hospital bills and other medical bills. Based on the study, the majority of Filipinos intended to finance their medical expenses from savings or debt. The study further indicated that forty (40) percent of respondents from various parts of the country expressed uncertainty on their capability to pay and settle their medical bills.

Table 5. Number and percentage distribution of patients in the degree of financial settlement strategy in terms of stand-alone risk.

\begin{tabular}{lcc}
\hline Degree of Financial Settlement Strategy & Frequency & Percent (\%) \\
\hline Very High (7 payments and above) & 4 & 16.0 \\
High (5-6 payments) & 10 & 40.0 \\
Moderate (3-4 payments) & 4 & 16.0 \\
Low (1-2 payments) & 7 & 28.0 \\
Total $\quad 25$ & 100 \\
$\quad$ Mean Score $=3.44$ (High) & & \\
\hline
\end{tabular}

Guaranteed payment. Results in Table 6 showed the number and percentage of patients who used guaranteed payment as a financial settlement strategy. Out of 212 respondents who used guaranteed payment as strategy, 118 patients had used the financial settlement strategy, 45 had moderate degree of financial settlement or made 3-4 payments; 35 had low or made 1-2 payments; while 14 had very high degree of financial settlement strategy who made seven payments or more. Majority, 5-6 payments were made and implied there was guaranteed payment.

Financial assistance and aid from different sources; government agencies and non-government organizations (NGOs) make payments while the patients are in admission, thus reducing the amount of the total hospitalization bill. There is reason to believe that patients or their folks pay a portion of the charges whenever funds are available. 
Table 6. Number and percentage of patients who used guaranteed payment as a financial settlement strategy.

\begin{tabular}{lcc}
\hline Degree of Financial Settlement Strategy & Frequency & Percent (\%) \\
\hline Very High (7 payments and above) & 14 & 6.6 \\
High (5-6 payments) & 118 & 55.7 \\
Moderate (3-4 payments) & 45 & 21.2 \\
Low (1-2 payments) & 35 & 16.5 \\
Total & 212 & 100 \\
$\quad$ Mean Score $=3.52($ High $)$ & & \\
\hline
\end{tabular}

Differences in the Extent of Financial Settlements of Discharged Patients and Selected Profile Data show the majority (56.2\%) of the respondents reside outside Roxas City, $43.8 \%$ from Roxas City; $85.7 \%$ were members of PhilHealth; $25(10.5 \%)$ had medical health insurance from private insurance companies and nine $(3.8 \%)$ had no medical health insurance. There were $78(32.9 \%)$ who were admitted for 4-6 days, 68 (28.7\%) admitted for 10 days and above, 68 (28.7\%) admitted for 7-9 days, and $23(9.7 \%)$ were admitted for 1-3 days. The admitted patients were $173(73.0 \%)$ in private rooms, $54(22.8 \%)$ in the ward, and $10(4.2 \%)$ in the ICU.

Table 7. Profile of the respondents.

\begin{tabular}{ccc}
\hline \multicolumn{1}{c}{ Profile } & Frequency & Percent (\%) \\
\hline Address & 117 & 43.8 \\
Within Roxas City & 120 & 56.2 \\
Outside Roxas City & 237 & 100 \\
Total & & \\
Medical Health Insurance & 9 & 3.8 \\
None & 203 & 85.7 \\
Philhealth & 25 & 10.5 \\
Private Insurance & 237 & 100 \\
Total & & \\
1-3 days & 23 & 9.7 \\
4-6 days & 78 & 32.9 \\
7-9 days & 68 & 28.7 \\
10 days and above & 68 & 28.7 \\
Total & 237 & 100 \\
Duration of Hospitalization & & \\
Ward & 54 & 22.8 \\
Private & 173 & 73.0 \\
ICU & 10 & 4.2 \\
Total & 237 & 100 \\
\hline
\end{tabular}

Extent of financial settlement of discharged patients

Table 8 shows the significant difference when grouped according to the selected profile. Results differed in the extent of financial settlements of discharged patients according to medical health insurance and insignificant differences were noted as to address, duration of hospitalization, and room accommodation. The F-value of 0.083 , sig. value of 0.343 for address, F-value of 1.873 , sig. value of 0.135 for duration of hospitalization and F-value of 1.322 , sig. value of 0.269 posited a higher significant value than 0.05 alpha. The null hypothesis, there is no significant difference on the extent of financial settlements of discharged patients considering the selected variables was accepted. This meant patients residing in and outside the city, based on duration of hospitalization and room accommodation were similar or no variation at all. This meant regardless of these factors, the patients experienced financial difficulty in the settlements of hospital bills. Whether they are living in the urban or rural area, they are duty-bound to pay hospital services when confined in private hospitals. However, people in the rural areas may have other sources of income coming out from salaries. Generally, quality of life in the urban area is better than in rural areas in terms of estimated regular income. 
However, during the duration of hospitalization, data indicated that discharged patients who were admitted for 1-3 days had the same extent of financial settlements than those who were admitted for 4-6 days, 7-9 days, and 10 days and above. Regardless of the number of days of hospitalization, the patients were able to settle their financial obligations at a high extent. As to room accommodation, the patients understand that being admitted in the ward is much cheaper than being in semi-private or private rooms. In some cases, though, rooms were assigned based on cases and the need for medical care such as the ICU but it did not affect the financial settlement in this study. Likewise, they may resort to loans and other sources to settle their financial obligations with the hospital.

Financial settlements and medical health insurance. Data show significant difference in the extent of financial settlements of discharged patients when respondents were grouped according to medical health insurance. The f-value of 8.566 had a significant value of 0.000 which was lower than 0.05 alpha. The computed value suggests the rejection of the null hypothesis which states that there is no significant difference on the extent of financial settlements when discharged patients were grouped according to medical health insurance. The results imply that the extent of financial settlements of discharged patients varied as to having medical health insurance or not. Post-hoc analysis revealed discharged patients with PhilHealth had a higher extent of financial settlements than those who had no medical health insurance and private medical health insurance, respectively. However, the deducted amount due to PhilHealth reduces the hospitalization cost. Lower percentage was observed than those with PhilHealth, patients with no medical health insurance paid to settle their financial obligations with the hospital to a high extent. The low financial settlement for patients with private medical health insurance may be due to longer private medical health insurance companies reimbursing the bill. As O'Riordan found, financial burden from medical bills hit those without insurance, low-income families, non-Hispanic black patients, and those with more comorbidities the hardest. The study found that two most vulnerable groups were patients from low-income families and those without insurance.

Table 8. Differences in the extent of financial settlements of discharged patients and selected profiles.

\begin{tabular}{|c|c|c|c|}
\hline \multicolumn{2}{|c|}{ Socio-demographic Profile F- Value } & Significant Value & Probability \\
\hline Address & 0.083 & 0.343 & n.s. \\
\hline Medical Health Insurance & 8.566 & 0.000 & s. \\
\hline Duration of Hospitalization & 1.873 & 0.135 & n.s. \\
\hline Room Accommodation & 1.322 & 0.269 & n.s. \\
\hline
\end{tabular}

Differences in the degree of financial settlement strategies of discharged patients and selected profile Data in Table 9 show the distribution of different profiles of the respondents in the degree of financial settlement strategies of discharged patients with their significant values, $\mathrm{F}$ values, and corresponding probability. The results show that there were significant differences in the degree of financial settlement strategies of discharged patients when they were grouped according to address, medical insurance, and duration of hospitalization. The data show that there was a significant difference in the degree of financial settlement strategies of discharged patients when respondents were grouped according to address. The computed value suggests the rejection of the null hypothesis which states that there is no significant difference in the degree of financial settlement strategies used in paying hospital charges. 0376 in the degree of financial settlement strategies of discharged patients when grouped according to address was significant at 05 . The results imply that in terms of address, discharged patients varied in the degree of financial settlement strategies. The data show that there was a significant difference in the degree of financial settlement strategies of discharged patients when respondents were grouped according to medical health insurance. This computed value suggests the rejection of the null hypothesis which states that there is no significant difference in degree of financial settlement strategies of discharged patients when respondents were grouped according to medical health insurance. Results show that there was a significant difference in the degree of financial settlement strategies of discharged patients when respondents were grouped according to duration of hospitalization. This computed value suggests the rejection of the null hypothesis which states that there is no significant difference in the degree of financial settlement strategies of discharged patients considering the duration of hospitalization. 
Table 9. Differences in the degree of financial settlement strategies of discharged patients and selected profile.

\begin{tabular}{lccc}
\hline \multicolumn{1}{c}{ Socio-demographic Profile } & $\mathrm{t} /$ F Value & Significant Value & Probability \\
\hline Address & -0.332 & 0.043 & $\mathrm{~s}$. \\
Medical Health Insurance & 16.243 & 0.000 & $\mathrm{~s}$. \\
Duration of Hospitalization & 18.392 & 0.000 & $\mathrm{~s}$. \\
Room Accommodation & 0.255 & 0.775 & n.s. \\
\hline
\end{tabular}

Relationship between the Extent of Financial Settlements and Degree of Financial Settlement Strategies Results on determining the relationship between the extent of financial settlement and degree of financial settlement strategies of discharged patients is shown in Table 6. Findings revealed a significant relationship in between the extent of financial settlement and degree of financial settlement strategies of discharged patients. The Pearson $r$ value of 0.317 had a significant value of 0.000 which was lower than 0.05 alpha. The Pearson $r$ value of 0.317 had a significant value of 0.000 which was lower than 0.05 alpha. The null hypothesis that there is no significant difference between the dependent variables was rejected. The results imply that the extent of financial settlement is significantly related to the degree of financial settlement strategies of discharged patients. The higher the extent of financial settlement, the higher the degree of financial settlement strategies. In the same manner, the lower the extent of financial settlement, the lower the degree of financial settlement strategies. Results indicated direct match between extent of financial settlement and degree of financial settlement strategies employed. Further making a series of payments means continually decreasing the amount of financial obligation to be settled. In credit terms, from the vantage view of the lender, in this case, the hospital, the borrower in this case, the patients making several payments to settle the financial account reflects the borrowers' commitment to settle financial obligations. The study found also that the more frequent staggered payments made by the patients, the higher the chances of settling financial obligations.

Table 10. Relationship between the extent of financial settlements and the degree of financial settlement strategies of discharged patients.

\begin{tabular}{lcccc}
\hline Variable & $\mathrm{N}$ & Pearson-r & $\begin{array}{c}\text { Significance } \\
\text { Value }\end{array}$ & Probability \\
\hline $\begin{array}{l}\text { Financial Settlement } \\
\begin{array}{l}\text { Financial Settlement } \\
\text { Strategies }\end{array}\end{array}$ & 237 & 0.317 & 0.000 & s. \\
\hline
\end{tabular}

\section{Conclusions}

Based on the findings of the study, the following conclusions are drawn:

1. The state of settlement of financial obligations of discharged patients at St. Anthony College of Roxas City, Inc. (Hospital) is remarkably high whereas unsettled accounts upon discharge was low.

2. The financial obligations of discharged patients were generally settled in cash, others adopt the financial settlement strategies of the hospital such as promissory notes and guaranteed payments.

3. Majority of the patients have government or medical health insurance from companies that reduce patients' financial obligations upon discharge.

4. The settlement of cost of hospitalization was in proportion to length of stay at the hospital, room accommodation and other services and medical health insurance of patients.

5. The hospitals offered settlement strategies for unsettled hospital bills and obligations of patients upon discharge.

\section{Implications}

Hospitals are people's health support systems. Other agencies can perform or duplicate the function of another but not in the case of hospitals. It has one major function that no other agency can perform. Since no one is exempted from illness, all is deemed to apportion part of his income for hospitalization. Not all the time, there are agencies who can help patients. The help should come from oneself. If hospitals will be incapacitated, nobody is in the position to cure and care for the sick. Thus, patients and guarantors with 
outstanding balance in hospitals should be able to settle their promissory notes. Whatever is the obligation of the patient become the obligation of the guarantor whether notarized or not provided signed by the person himself, it becomes his liability.

\section{References}

Beck, T., Grunert, J., Neus, W., \& Walter, A. (2017). What determines collection rates of debt collection agencies? Financial Review, 52(2), 259-279.

Kriebel, J. \& Yam, K. (2019). Forecasting recoveries in debt collection: Debt collectors and information production. European Financial Management, 1(1), 1-23

Otremba, M., Berland, G., \& Amon, J. (2015). Hospitals as debtor prisons. Lancet Glob Health, 7(2), 111123.

Yates, R., Brookes, T., \& Whitaker, E. (2017). Hospital detentions for nonpayment of fees: A denial of rights and dignity. Chatham: Centre on Global Health Security, 3(7), 65-77.

Acosta, P. (2018). When can hospital detention be valid? The Manila

Times. Retrieved August 20, 2020 from: https://www.manilatimes.net Acosta, P. (2017). How can a hospital recoup costs from treating a penniless patient? Retrieved August 20, 2020 from: manilatimes.net/

O'Riordan, M. (2020). Nearly half of diabetic patients struggle to pay medical bills. Retrieved October 2, 2020 from: https://www.tctmd.com/ 